\title{
Estudo da Variação de Temperatura entre Circunferências Concêntricas Utilizando o Método das Diferenças Finitas
}

\author{
Adilandri Mércio Lobeiro Julia M. N. Mimura Mariana S. Ribeiro \\ Departamento Acadêmico de Matemática, DAMAT, UTFPR \\ 87301-899, Campus Campo Mourão, PR \\ E-mail: alobeiro@utfpr.edu.br, juliamimura@hotmail.com, marisr-08@yahoo.com.br
}

\section{Clicia Geovana Alves Pereira Juan Amadeo Soriano Palomino}

Departamento de Ciências, DCI, UEM

Departamento de Matemática, DMA, UEM

87360-000, Campus Goioerê, PR

E-mail: cgapereira2@uem.br, jaspalomino@uem.br

\section{RESUMO}

A temperatura $y(x)$ na região entre as circunferências concêntricas de raios $x_{0}=a$ e $x_{1}=b$, onde $a<b$, é determinada a partir do Problema de Valor de Contorno (PVC)

$$
\begin{gathered}
x y^{\prime \prime}(x)+y^{\prime}(x)=0 \\
y(a)=y_{0}, y(b)=y_{n+1},
\end{gathered}
$$

onde $y_{0}$ e $y_{n+1}$ são contantes [2].

O objetivo deste trabalho é obter a solução analítica e numérica de um estudo de caso do PVC (1). Para isso, considera-se o PVC

$$
\begin{gathered}
x y^{\prime \prime}(x)+y^{\prime}(x)=0 \\
y(1)=50, y(4)=100 .
\end{gathered}
$$

A solução analítica é dada por

$$
y(x)=\frac{25}{\ln 2} \ln x+50 .
$$

Para obter a solução numérica utilizou-se o Método das Diferenças Finitas (MDF). Tal método consiste em escolher um número inteiro $n>0$ e discretizar o domínio $[a, b]$ em $n+1$ subintervalos de tamanho $h=(b-a) /(n+1)$, obtendo-se $n+2$ pontos $x_{0}=a, x_{1}, x_{2}, \cdots, x_{n+1}=b$ [1]. Nos pontos de malha interiores, $x_{i}$, para $i=1, \cdots, n$, a equação diferencial a ser aproximada é

$$
x_{i} y^{\prime \prime}\left(x_{i}\right)+y^{\prime}\left(x_{i}\right)=0 .
$$

A ideia do MDF é substituir as derivadas da equação (4) pelas fórmulas de Diferenças Centradas. Desta forma, expandindo a função $y\left(x_{i}\right)$ em Série de Taylor, centrada em $\xi$, e adotando $h=x_{i}-\xi$ pequeno, pode-se ignorar termos que envolvam $h^{2}$ e ordem superior ( $h^{3}$ e ordem superior, respectivamente) e obtém-se aproximações para

$$
y^{\prime}\left(x_{i}\right)=\frac{y\left(x_{i+1}\right)-y\left(x_{i-1}\right)}{2 h}
$$

$\mathrm{e}$

$$
y^{\prime \prime}\left(x_{i}\right)=\frac{y\left(x_{i-1}\right)-2 y\left(x_{i}\right)+y\left(x_{i+1}\right)}{h^{2}} .
$$


Adotando $y_{i}=y\left(x_{i}\right)$ e substituindo as equações (5) e (6) na equação (4), um MDF é obtido utilizandose essa equação com as condições de contorno $y(1)=50$ e $y(4)=100$

$$
\mid \begin{aligned}
& \left(x_{i}-\frac{h}{2}\right) y_{i-1}-2 x_{i} y_{i}+\left(x_{i}+\frac{h}{2}\right) y_{i+1}=0 \\
& y(1)=50, y(4)=100,
\end{aligned}
$$

com $i=1, \ldots, n$. A solução numérica consiste em obter as temperaturas $y_{i}$ nos pontos discretizados. Para isso, basta resolver o sistema de equações lineares (7) onde a matriz dos coeficientes é uma matriz tridiagonal de ordem $n \times n$ [1]. Para obter a solução numérica do PVC (2) utilizou-se o software Maple 17 para implementar o MDF.

Neste estudo de caso, discretizou-se o domínio [1;4] em 30 subintervalos de tamanho $h=0,1$, obtendo 31 pontos $x_{0}=1, x_{1}=1,1, \cdots, x_{29}=3,9, x_{30}=4$ e formando um sistema de 29 equações e 29 incógnitas, sendo as incógnitas as aproximações $y_{i}$ em cada um dos pontos discretizados $x_{i}$.

A Figura 1 apresenta os gráficos de ambas as soluções, deixando claro a proximidade entre os valores numéricos e analíticos.

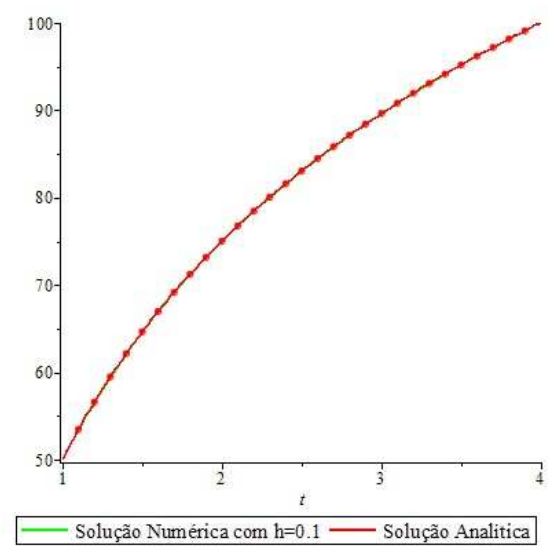

Figura 1: Função Temperatura

A Tabela 1 apresenta uma comparação mais clara para alguns dos pontos calculados.

Tabela 1: Resultados e Erro

\begin{tabular}{cccccc}
\hline$i$ & $x_{i}$ & $y_{i}$ & $y\left(x_{i}\right)$ & Erro absoluto & Erro Relativo \\
\hline 0 & 1,0 & 50 & 50 & 0 & - \\
1 & 1,1 & 53,43595451 & 53,43758809 & 0,001633580 & 0,000030570 \\
10 & 2,0 & 74,99578340 & 75,00000001 & 0,004216610 & 0,000056221 \\
20 & 3,0 & 89,62187366 & 89,62406253 & 0,002188870 & 0,000024423 \\
29 & 3,9 & 99,08664501 & 99,08685309 & 0,000208080 & 0,000002100 \\
30 & 4,0 & 100 & 100 & 0 & - \\
\hline
\end{tabular}

Com base no erro relativo, pode-se concluir a eficácia do método quanto à aproximação dos resultados.

Palavras-chave: Maple, Diferenças Finitas, Equação Diferencial

\section{Referências}

[1] R. L. Burden, D. J. Faires, “Análise Numérica”, $1^{a}$ Edição, São Paulo, Editora Thomson, 2003.

[2] S. C. Chapra, "Métodos Numéricos para Engenharia", 5. ed, São Paulo, SP: McGraw-Hill, 2008 